\title{
Penyuluhan Pra Nikah Dalam Perspektif Islam Sebagai Upaya Meningkatkan Pengetahuan Tentang Pernikahan Islam
}

\author{
${ }^{1}$ Israfil, ${ }^{2}$ Muzakir Salat, ${ }^{3}$ Aminullah, Subakti4 \\ 18.2Fakultas Hukum, Universitas Mataram, J1. Majapahit No.62, Gomong, \\ Kec. Selaparang, Kota Mataram, Nusa Tenggara Bar. 83115 \\ ${ }^{3 \& 4}$ Universitas Pendidikan Mandalika. 1. Pemuda No.59A, Dasan Agung \\ Baru, Kec. Mataram, Kota Mataram, Nusa Tenggara Bar. 83125 \\ Email Korespondensi: Israfil@unram.ac.id
}

Diterima: Juni 2021; Revisi: Juni 2021; Diterbitkan: Juni 2021

\begin{abstract}
Divorce in NTB may increase due to the prevalence of underage marriages (19 years and under), lack of understanding of the things that must be prepared before marriage. This condition becomes the basis for doing service with the aim of increasing knowledge and understanding of Islamic marriage through Pre-Marriage counseling activities from an Islamic perspective. Partners in this activity are the Gelogor village community, West Lombok district, totaling 20 people. The implementation method is lecture, discussion, and question and answer. The steps of planning, action, and evaluation activities. The results of the pre-test of partners' understanding of premarital marriage in the Islamic perspective got an average score of 50 and the posttest results averaged 90 with an average increase of 33\%. This shows that the extension activities have an impact on increasing the understanding and knowledge of partners. Although there is an increase and understanding of partners, it is still necessary to carry out socialization and mentoring on an ongoing basis.
\end{abstract}

Keywords: Pre marriage, Islamic perspective, knowledge, Islamic marriage

\begin{abstract}
Abstrak
Perceraian di NTB makin meningkat diakibatkan maraknya pernikahan dibawah umur (19 tahun kebawah), kurangnya pemahaman tentang hal-hal yang harus persiapkan sebelum melakukan pernikahan. kondisi ini menjadi dasar melakukan pengabdian dengan tujuan meningkatkan pengetahuan dan pemahaman tentang pernikahan islam melalui kegitan penyuluhan Pra Nikah dalam perspektif Islam. Mitra dalam kegitan ini adalah masyarakat desa Gelogor kabupaten Lombok Barat yang berjumlah 20 orang. Metode pelaksanaan dengan ceramah, diskusi dan tanya jawab. Langkah-langkah kegitan perencanaa, tindakan, dan evalusi. Hasil pre test pemahaman mitra tentang pra nikah dalam Perspektif Islam mendapatkan nilai rata-rata 50 dan hasil posttest rata-rata 90 dengan rata-rata peningkatan 33\%. Ini menunjukkan bahwa kegiatan penyuluhan memberikan dampak pada peningkatan pemahaman dan pengetahuan mitra. Meskipun terjadi peningkatan dan pemahaman mitra masih perlu dilakukan sosialisasi dan pempingan secara berkelanjutan.
\end{abstract}

Kata Kunci: Pra nikah, Perspektif Islam, pengetahuan, pernikahan islam

How to Cite: Israfil., Salat M., \& Aminullah. (2021). Penyuluhan Pra Nikah dalam Perspektif Islam Sebagai Upaya Meningkatkan Pengetahuan Tentang Pernikahan Islam. SASAMBO: Jurnal Abdimas (Journal of Community Service). 3(2), 92-98. DOI: 10.36312/sasambo.v3i2.483 
LATAR BELAKANG

Pernikahan merupakan bentuk kebutuhan individu dan social setiap insan laki-laki dan perempuan untuk membentuk hubungan yang terlahir dari rasa cinta dan kesadaran. (Ibn 'Abd al-Raziq \& Saikhu, 2006) Pernikahan sangat diajurkan dalam agama islam, karena sebagai sarana mempertahankan keturunan dan memperbanyak populasi muslim. Pernikahan menjadi persoalan yang sangat utama dan penting dalam agama islam, bahkan karena pentignya Rasulullah SAW bersambda "Barang siapa menikah, maka ia telah melengkapi separuh dari agamanya. Dan hendaklah ia bertaqwa kepada Allah dalam memelihara yang separuhnya lagi" (HR Albaihaqi dan Alhakim) (Damayanti \& Fitriani, 2020). (Nurfauziyah, 2017) menyatakan bahwa pernikahan sebagi sarana yang mulia untuk mengatur kehidupan berumah tangga, keturunan, dan sebagai salah satu jalan perkenalan antara suatu kaum dengan kaum yang lainnya, dan perkenalan itu akan menjadi jalan untuk menyampaikan pertolongan antara satu dengan yang lainnya.

Pernikahan yang sukses adalah pernikahan yang dapat membagun rumah tangga bahagia dan untuk membagun rumah tangga yang bahagia dibutuhkan pondasi pernikahan yang kuat yang didasarkan atas syariatsyariat islam yang telah ditentukan. Dengan adanya pondasi pernihakan yang kuat maka akan terbagun keluarga yang syakinah wahdah warahmah. (Shalih;, 2007) menyatakan bahwa penikahan yang dilandasi dengan pondasi agama yang kuat, maka akan menuai sukses dan masyarakat yang suksespun akan tercipta.

Membangun pernikahan yang sukses dan bagian pada kenyataannya tidaklah mudah. Data Badan Pusat Statistik Provensi Nusa Tenggara Barat (BPSP NTB) menunjukkan dari 49.25 pasangan menikah pada tahun 2014, 3.01 pasangan diantaranya bercerai (BPSP NTB, 2015). Kementrian agama menyatakan bahwa secara nasional tingkat perceraian dalam lima tahun terakhir makin meningkat yakni pada tahun 2009 prosentase $10 \%$ dan peningkatan mencapai $14.6 \%$ pada tahun 2013 (BKKBN NTB, 2020). Tingginya angka perceraian di NTB salah satunya karena pernikahan diusia muda cukup banyak dengan rata-rata usia perkawinan 19 tahun kebawah selain itu masih adanya ketidaksiapan dari segi ekonomi, psikologi, kesiapan mental, life skill, intelektual, social dan moral (BKKBN NTB, 2020; Rini, 2016).

Mitra dalam kegitan pengabdian ini adalah Gelogor Kabupaten Lombok Barat. Desa Gelogor merupakan salah satu desa dari 10 desa yang ada dikecamatan Kediri yang terdiri dari 7 dusun dengan jumlah penduduk 6411 orang yang terdiri dari 2145 KK (Profil, 2019). Survey yang dilakuakn didesa Gelogor didapatkan bahwa angka perceraian masih cukup tinggi yang disebabkan karena adanya pernikahan dibawah umur, social, ekonomi pemahaman dan pengetahuan dalam membangun rumah tangga yang baik. Kondisi ini sangat memperihatinkan karena berdampak pada kehidupan social, keberlanjutan hak asuh dan pendidikan anak, broken home, Stres dan masih banyak dampak yang lain.

Kondisi memprihatinkan ini menjadi landasan utama kegitan penyuluhan pra nikah ini dilaksanakan. (Jazil, 2020) Pendidikan pranikah merupakan pemberian bekal secara sistematis berupa petunjuk, 
penasihatan, bimbingan serta pengarahan kepada calon pengantin sebelu melanjutkan akad nikah yang dilakukan oleh pembimbing atau fasilitaor. Dampak adanya pendidikan pranikah ini adalah perubahan sikap, membangun mental yang positif, menyelesaikan problem, keefisiensi personal, meminimalisir terjadinya perceraian dan pernikahan dini (Hamzanwadi, 2020). (Jazil, 2020) menyatakan pasangan yang mengikuti bimbingan pranikah merasa lebih percaya diri dan lebih siap menjalani kehiduan berumah tangga. (Karimulloh et al., 2020) adanya penyuluhan pra nikah menunjukkan adanya peningkatan pengetahuan pendidikan pranikah baik dari perspektif Islam, Psikologi maupun finansial. (Parmujianto, 2020) bimbingan pranikah efektif dalam meningkatkan percaya diri dalam menjalankan pernikahan dan efektif dalam meingkatkan pemahaman tentang pranikah. Sedangkan (Karimulloh et al., 2020) menyatakan bahwa hasil penyuluhan menunjukkan adanya peningkatan pengetahuan partisipan mengenai persiapan pra nikah berdasarkan perspektif islam. Berdasarkan kajian di atas tujuan kegitaan pengabdian ini adalah untuk menigkatkan pengetahuan tentang pendidikan pranikah berdasarakan perspektif islam.

\section{METODE PELAKSANAAN}

Pelaksanaan kegitan pengabdian ini dengan mengunakan metode ceramah, diskusi dan Tanya jawab. Langkah-langkah kegiatan 1) perencanaan, 2) Pelaksanaan, dan 3) evaluasi. Mitra dalam kegitan ini adalah masyarakat desa Gelogor Kabupaten Lombok Barat yang berjumlah 20 orang.

1. Perencanaan

Persipan pelaksanaan pengabdian dilakukan mulai dari survey lokasi kegitan, penyelesaian administrasi surat-menyurat, menyipakan alat dan bahan yang dibutuhkan selama kegiatan berlansung, menyiapkan modul, materi dalam bentuk power point, instrument evaluasi.

2. Pelaksanaan

Kegitan pengabdian dilaksankan dengan tiga tahap yakni; 1) Sebelum dilakukannya pemaparan materi diberikan pre-test atau tes awal yang bertujuan untuk mengetahui pemahaman awal mitra. pre-test diberikan saat acara dimulai, 2) pemaparan materi, dan 3) diberikan posttest untuk melihat apakah ada peningkatan antara sebelum diberikan materi dengan sesudah diberikan materi.

3. Evaluasi

Evaluasi dilakukan setelah selesai kegitan, ini bertujuan untuk mengetahui sejauh mana capaian proses dan respon dari mitra selama kegitan. Evaluasi dilakukan secra lansung dengan Tanya jawab.

Mitra berpartisipasi penuh dalam membantu mempersipakan kegitan seperti meyediakan lokasi kegitan, menyiapkan alat dan bahan serta kebutuhan selam kegitan pengabdian berlangsung.

\section{HASIL DAN PEMBAHASAN Perencanaan}

Proses pelaksanaan kegitan dapat berjalan dengan baik karena adanya kerjasama antara tim Pengabdian masyarakat dengan mitra. Dalam hal ini mitra berkontribusi penuh dalm menyiapkan waktu, alat, bahan serta kebutuhan-kebutuhan yang digunakan selam kegiatan pengabdian. 
Tim pengabdian sebelum melaksankan penyuluhan terlebih dahulu menyiakan beberapa hal antara lain;

1. Instrume evaluasi pretes dan posttest untuk meninjau tingkat pemahaman mitra terkait dengan materi yang akan disajikan. Instrument berupa soal-soal pilihan ganda yang terdiri dari 10 item.

2. Modul pra nikah dalam perspektif islam, modul ini diberikan ke setiap peserta dengan tujuan agar lebih mudah memahami materi yang akan disajikan (Arifah, 2010) menyatakan bahwa dengan penggunaan modul dalam pembelajaran dapat meningkatkan pemahaman dan pengetahuan. Keberadaan modul dalam penyuluhan dapat membatu memudahkan pembicara dalam menyampikan materi hal ini karena peserta selain mendengarkan peserta juga dapat membaca dan mengulang kembali. (Baroroh et al., 2018) menyatakan kegitan edukasi dengan metode modul, ceramah dan diskusi dapat meningkatkan pemahaman dan pengetahuan kader-kader kesehatan .

\section{Pelaksanaan}

Pelaksanaan penyuluhan dilakukan di aula kantor desa Gelogor yang diawali dengan pemberian pre tes, pembekalan materi, posttest dan evaluasi secara keseluruhan dari kegitaan. Hasil analisis pre tes dan posttest disajikan dalam bentuk diagram sebagai berikut;

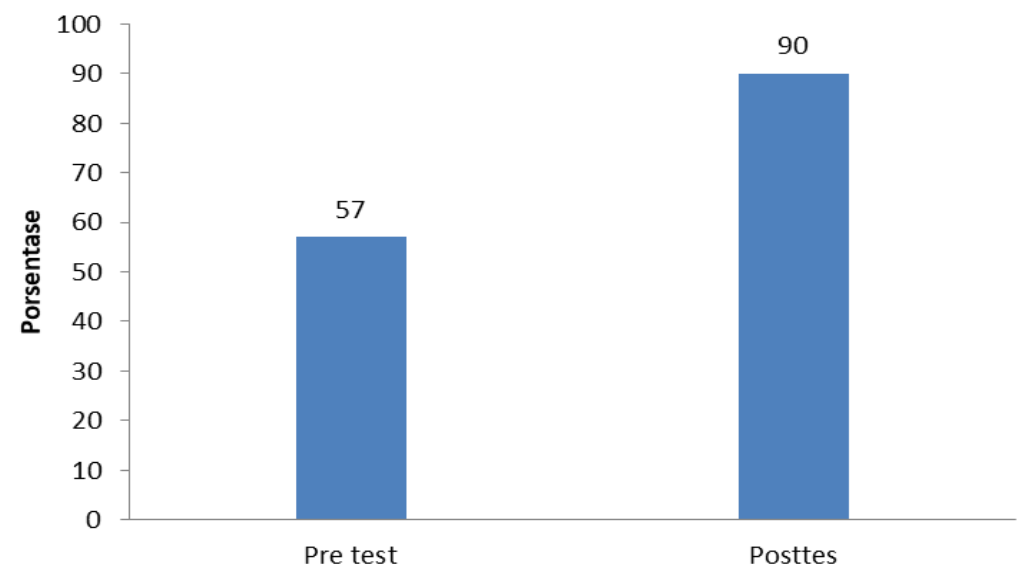

Gambar 1. Diagram hasil analisis Pre tes dan Posttest pemahaman mitra

Diagram di atas menunjukkan bahwa adanya peningatan pemahaman mitra setelah dilakukan penyuluhan, peningkatan pemehaman sebensar $33 \%$ yakni dari rata-rata 57 menjadi rata-rata 90. Ini menggambrakan bahwa peyuluhan yang dilakukan dapat memberikan dampak positif terhadap tingkat pemahaman mitra tentang pra nikah berdasarkan perspektif Islam.

Pembekalan pemahaman tentang Pra nikah sangat penting dilakukan untuk menyiapkan remaja usia nikah dan calon suami istri dalam membangun rumah tangga yang baik. Pembekalan-pembekalan tersebut dapat diberikan melalui kegitaan penyuluhan, pendidikan atupun Kursus. (Ridho, 2018) kursus pra nikah penting dilakukan untuk membekali pengetahuan, pemahaman, keteampilan dan penumbuhan kesadaran kepada remaja usia nikah tentang kehidupan rumah tangga dan keluarga. Sedangkan (Amelia et al., 2020) menyatakan layanan bimbingan pra nikah sebagi upaya pemberian bantuan, informasi kepada calon pengantin yang dilakukan sebelum melaksanakan pernikahan agar dapat memahmi makna 
pernikahan dan kehidupan rumah tangga serta untuk melatih mental calon pengantin.

Pernikahan merupakan komitmen yang dibangun oleh pasangan lakilaki dan perempuan untuk melansungkan kehidupan bersama dalam rumah tangga. (Damayanti \& Fitriani, 2020) pernikahan adalah kodrat ilahi atau ketentuan sang pencipta dan menjadi kebutuhan setiap individu manusia untuk melansungkan kehidupan Sedangkan menyatakan bahwa pernikahan adalah komitmen emosiaonal dan legal daru dua orang untuk berbagi kedekatan emosional dan fisik, berbagi tugas dan sumber daya ekonomi. Pernikahan yang sakinah mawaddah wa rahmah menjadi dambaan setiap pasangan suami istri, akan tetapi untuk mencapai hal tersebut dibutuhkan keterampilan, pengetahuan, dan kesiapan mental, psikologi, life skill, intelektual, social dan moral.

\section{Evaluasi}

Evaluasi dilakukan secara menyeluruh dengan cara mewawancarai mitra setelah kegitan penyuluhan selesai. Materi evaluasi antara lain, respon peserta terhadap kegiatan dan proses pelaksanaan kegitan. Respon peserta terhadap pelaksanaan pengabdian sangat baik hal ini ditunjukkan oleh motivasi dan semangat peserta mengikuti semua sesi kegitan dengan tertib dan baik. Sedangkan proses pelaksanaan berjalan dengan baik dengan indicator setiap sesi mulai dari persiapan sampai proses evaluasi semua terlaksan sesuai dengan perencanaan. Meskipun ada beberapa kendala teknis seperti mati lapu, dan beberapa peserta terlambat dating karena hujan.

\section{KESIMPULAN}

Kegitan penyuluhan pra nika berdasarkan perspektif islam secara keseluruhan berjalan dengan baik sesuai perencanaan yang telah dibuat. Kegitan penyuluhan yang dilakukan dapat meningkatkan pemahaman mitra hal ini sesai dengan hasil analisis hasil pretes dan posttes dimana hasil pretes rata-rata mendapatkan 57 sedangkan posttest rata-rata 90 dengan porsentasi peningkatan sebesar 33\%.

\section{REKOMENDASI}

Meskipun terjadi peningkatan pemahaman, kegitan penyuluhan masih perlu dilakukan secara kontinu, selain itu perlu adanya pendampinganpendampingan agar masyarat mitra benar-benar paham akan pentingnya persiapan pra nikah sebelum melansungkan pernikahan

\section{UCAPAN TERIMAKASIH}

Kegiatan ini terlaksana karena dukungan dari berbagai pihak antara Fakultas Hukum Universitas Mataram, Pemerintahan desa Gelogor dan peserta mitra.

\section{DAFTAR PUSTAKA}

Amelia, N., Efendi, D. I., \& Marfuah, L. A. (2020). Layanan Bimbingan Pranikah dalam Meningkatkan Keharmonisan Keluarga di KUA Cileunyi. Irsyad: Jurnal Bimbingan, Penyuluhan, Konseling, Dan Psikoterapi Islam, 8(1), 41-58. https://doi.org/10.15575/irsyad.v8i1.1480 
Arifah, S. (2010). Pengaruh pendidikan kesehatan dengan modul dan media visual terhadap peningkatan pengetahuan dan sikap wanita dalam menghadapi menopause (Studi eksperimen pada wanita premenopause di Desa Sumbermulyo

https:/ /digilib.uns.ac.id/dokumen/detail/13325/Pengaruhpendidikan-kesehatan-dengan-modul-dan-media-visual-terhadappeningkatan-pengetahuan-dan-sikap-wanita-dalam-menghadapimenopause-Studi-eksperimen-pada-wanita-premenopause-di-DesaSumbermulyo

Baroroh, H. N., Utami, E. D., Maharani, L., \& Mustikaningtias, I. (2018). Peningkatan Pengetahuan Masyarakat Melalui Edukasi Tentang Penggunaan Antibiotik Bijak dan Rasional. Ad-Dawaa' Journal of Pharmaceutical Sciences, 1(1), Article 1. https://doi.org/10.24252/djps.v1i1.6425

BKKBN NTB. (2020). KURSUS PRANIKAH (Persiapan Kehidupan Berkeluarga) $-B K K B N \mid$ NTB. http://ntb.bkkbn.go.id/?p=1695

BPSP NTB. (2015). Badan Pusat Statistik Provinsi Nusa Tenggara Barat. https://ntb.bps.go.id/statictable/2015/11/11/158/persentasependuduk-usia-10-tahun-ke-atas-menurut-kab-kota-dan-statusperkawinan-2014.html

Damayanti, I., \& Fitriani, E. (2020). Pelatihan Pranikah Berbasis Pengetahuan dan Keterampilan Bagi Pasangan Yang Akan Menikah Pada KUA Marpoyan Damai Pekanbaru | Damayanti | MENARA RIAU. http:/ / ejournal.uinsuska.ac.id/index.php/Menara/article/view/12482

Hamzanwadi. (2020). Konseling Pra-Nikah dengan Pendekatan Islami Bagi Remaja Menggunakan Al-Qur'an Dalam Meminimalisir Perceraian. Jurnal Al-Irsyad: Jurnal Bimbingan Konseling Islam, 2(1), 123-136.

Ibn 'Abd al-Raziq, U. ibn K., \& Saikhu, A. (2006). Panduan lengkap nikah (dari A sampai Z). Pustaka Ibnu Katsir.

Jazil, A. (2020). Eksistensi Bimbingan Perkawinan Pranikah di Wilayah Kecamatan Ujung Tanah Kota Makassar. Al-Mizan, 16(1), 1-26. https://doi.org/10.30603/am.v16i1.1405

Karimulloh, K., Kusristanti, C., \& Triman, A. (2020). Program Pra Nikah dalam Pendekatan Islam, Psikologi dan Finansial di Era Pandemi Covid-19. Info Abdi Cendekia, 1(2), Article 2. http:/ / iac.yarsi.ac.id/index.php/iac/article/view/34

Kellett, K. (2010). MARRIAGES \& FAMILIES: INTIMACY, DIVERSITY, AND STRENGTHS (5th ed.) By David H. Olson and John Defrain: Boston: McGraw Hill, 2006489 pages, \$92.19 (hardcover) ISBN 0-0732-0951-1. Educational Gerontology, 36(5), 447-448. https://doi.org/10.1080/03601271003608902

Nurfauziyah, A. (2017). Bimbingan Pranikah bagi Calon Pengantin dalam Mewujudkan Keluarga Sakinah. Irsyad: Jurnal Bimbingan, Penyuluhan, Konseling, Dan Psikoterapi Islam, 5(4), 449-468.

Parmujianto. (2020). Efektifitas Bimbingan Penyuluhan Usia Pra Nikah Bagi Calon Pengantin Di Kabupaten Pasuruan | Al Qodiri: Jurnal Pendidikan, Sosial dan

Keagamaan. http://ejournal.kopertais4.or.id/tapalkuda/index.php/qodiri/article/vi ew/4052 
Profil, D. (2019). Profil Desa Gelogor. Desa Gelogor. https://desagelogor.wordpress.com/

Ridho, M. (2018). Urgensi Bimbingan Pra Nikah Terhadap Tingkat Pencerian. JIGC (Journal of Islamic Guidance and Counseling), 2(1), 6378. https://doi.org/10.30631/jigc.v2i1.8

Rini, L. C. (2016, October 11). Tingkat Perceraian di NTB Sangat Tinggi. Republika Online. https://republika.co.id/berita/nasional/umum/16/10/11/oew2av299 -tingkat-perceraian-di-ntb-sangat-tinggi

Shalih;, S. F. (2007). Untukmu Yang Akan Menikah Dan Telah Menikah (Jakarta) [Text]. Pustaka Al Kautsar. http://library.fip.uny.ac.id/opac/index.php?p=show_detail\&id $=6322$ 